\title{
International perspective on health impact assessment in urban settings
}

\section{Salim Vohra}

Centre for Health Impact Assessment, Institute of Occupational Medicine, UK Email: salim.vohra@iom-world.org

\begin{abstract}
Health impact assessment is being used to support and deliver healthy and sustainable communities in major urban areas around the world. This article discusses some of the latest international developments in the use of health impact assessment in urban settings: in North America, Europe, Africa, Asia and Australasia. It outlines the implications of this work and describes some of the challenges facing practitioners in predicting health impacts and providing solutions to protecting and enhancing health and wellbeing in urban settings.
\end{abstract}

HIA is a systematic approach to identifying the differential health and wellbeing impacts of proposed plans and projects within a democratic, equitable, sustainable and ethical use of evidence framework. The goal is that positive health impacts are maximised and negative health impacts minimised within affected, or potentially affected, populations. ${ }^{1,2}$ It uses a range of structured and evaluated sources of qualitative and quantitative evidence that include public and other stakeholders' perceptions and experiences as well as public health, epidemiological, toxicological and medical knowledge. It aims to influence policy and decision-making by:

- providing a rigorous analysis of the potential impacts and options for enhancing positive impacts

- mitigating negative ones, and

- reducing any health inequalities that might arise from a proposed policy, plan, program or project.

Over the last three years, health impact assessment (HIA) has come of age and gone global. There are exciting developments, at policy and project levels, in North America, Europe, Africa, Asia and Australasia. This article describes some examples of the innovative HIA work occurring in each of these continents.

\section{North America}

Unlike the USA, Canada has a longstanding record in the field of HIA, healthy public policy and the consideration of the health impacts of policies, plans, programs and projects. $^{3,4}$ Only in the last few years has HIA gathered momentum in the USA, with the growing recognition that health and wellbeing are critical issues for major urban areas. $^{5}$ Leading institutions, notably the Centers for Disease Control and Prevention (CDC) in Atlanta, have begun to carry out HIAs on urban development plans and projects. ${ }^{6-8}$

One example of the imaginative work happening in North America is the work of the Design for Health initiative. This collaboration between the Metropolitan Design Center at the University of Minnesota and Blue Cross and Blue Shield of Minnesota, two major health insurance associations, aims to bridge the gap between community design, healthy living and land development planning. ${ }^{9}$ The Design Center's work is done by an interdisciplinary team with backgrounds in architecture, landscape architecture, planning, public health and landscape ecology. They have created a HIA tool and a set of HIA materials and information for other agencies and organisations in Minnesota to use when developing new urban plans and projects.

\section{Europe}

HIA has been practised in Europe for almost a decade with the UK, Finland and the Netherlands among others being major proponents. ${ }^{10}$ In Europe the major driving forces for the way HIA is being used in urban settings have been the health inequalities, sustainability and climate change agendas.

One example of the leading edge HIA activity in Europe is the work of the London Healthy Urban Development Unit. This Unit is investigating the links between urban planning and health and has developed a range of HIA tools to help improve health and wellbeing in London. ${ }^{11}$ Their financial model is the first of its kind internationally to estimate the capital and revenue costs of health-care services for new housing developments and extensions to existing urban areas. It is also pioneering the use of Geographical Information Systems to map existing health, social, leisure and cultural facilities and plan the situation of new facilities to ensure that they are evenly distributed and accessible to all. 


\section{Africa}

In Africa, HIA, as part of environmental health impact assessment, has been practised by major development agencies for over two decades and, similar to other southern regions and continents, has a strong history of doing social impact assessment alongside and within environmental impact assessment. ${ }^{12,13}$ The major driving force for HIA practice in Africa is the double burden of disease that many middle-income countries are facing from both infectious disease, such as HIV/AIDS and malaria, as well as the so-called developed country chronic diseases, such as obesity, heart disease and cancer. In addition, they need to ensure that economic development projects enhance the health and wellbeing of affected communities.

An example of a group undertaking groundbreaking HIA work is the Development Bank of Southern Africa in South Africa. It is currently working to mainstream HIA by embedding the consideration of health impacts within its existing environmental, social, economic, technical, financial and institutional appraisal processes for investment funds and technical assistance. ${ }^{14}$ The Bank is using an organisational development model to raise awareness of HIA and is developing health impact guidance and training for the Bank's in-house specialists, external clients and partners.

\section{Asia}

Similar to the African situation, development and the health burden from infectious and chronic diseases have been drivers for the use of HIA in Asia. HIA has been on the agenda since 2000, with Thailand and Laos leading the way. ${ }^{15-17}$ Both Thailand and Laos are embedding HIA within the environmental impact assessment framework; however, the HIA legislation in Thailand has gone beyond environmental impact assessment and taken a more holistic and far-reaching perspective on assessing the health and wellbeing implications of new plans and projects.

One example of the pioneering work in Asia is that of the Health Systems Research Unit in Thailand. ${ }^{18}$ This work has highlighted the importance of history, culture and spirituality in enhancing individual and community wellbeing. In its HIA work on high-rise developments and urban planning in Chiang Mai, the Unit showed that unplanned development was changing the historical, cultural and spiritual significance that Chiang Mai, with its beautiful architecture and temples, has in the Lanna territory. This change, in turn, was affecting the health and wellbeing of the residents of Chiang Mai.

\section{Australasia}

Australia and New Zealand have a long history of HIA with both countries having had national drivers to incorporate health and wellbeing issues within the environmental impact assessment process and the sustainability agenda, and as part of the healthy urban planning movement. ${ }^{19,20}$ The drivers for HIA have been health equity and the recognition that health and wellbeing are linked with where people live, work and play. Both countries have undertaken HIAs at national, regional and local levels. Examples of urban HIAs include the Shellharbour Foreshore Management Plan and the South East Queensland Regional Plan in Australia, and the Christchurch Urban Development Strategy and Greater Wellington Regional Land Transport Strategy in New Zealand.

An example of cutting edge HIA work in Australasia is that from the Centre for Health Equity Research, Training and Evaluation (CHETRE). They have developed a learning-by-doing approach to embedding HIA in the health and non-health agencies working in NSW. ${ }^{21}$ This approach involves supporting and mentoring health and non-health professionals to identify, plan for, carry out and follow HIAs on new proposals on which these professionals are working. This approach has raised awareness of the value of HIA and built the capacity of agencies in NSW to undertake HIA.

\section{The future of HIA in urban settings}

These varied examples show the breadth and depth of HIA practice in urban settings around the world. At one end of the spectrum there is a discernable global movement to undertake separate HIAs on urban policies, plans, programs and projects. At the other, there is a concerted push to integrate HIA into other forms of impact assessment, such as environmental impact assessment, social impact assessment and strategic environmental assessment, as well as to incorporate health into the wider sustainability agenda at national, regional and local levels. ${ }^{22}$ The 21 st Century is likely to see a blossoming of public health, in a similar way to sustainability, to once again become an integrated part of policy and practice. At policy level, policies and plans from land use, transport and defence to education, crime and social welfare will integrate the assessment of potential health impacts within their policy and plan-making processes. Similarly, at project level, whether it is nuclear power stations and energy-fromwaste facilities or housing and transport projects, all major projects will undergo some form of assessment of their potential health impacts whether as a separate HIA or as an integrated component within an environmental or social impact assessment.

However, there are three big challenges facing HIA in urban settings. First, the need to develop a robust and broad theoretical foundation that takes on board theoretical understandings from fields as diverse as urban planning and design; risk perception, communication and management; sociology and anthropology; environmental psychology and economics; as well as the more classical epidemiology, toxicology, health promotion and public 
health. ${ }^{23}$ Second, to do more systematic follow-ups, plans and projects to evaluate: their actual health impacts, the predictions made in any HIAs that were undertaken on them and the value HIA had in changing the final design and implementation. ${ }^{24}$ And third, to learn more from each other both within countries and internationally. The health issues we are facing, both North and South, East and West, have more similarities than differences. It is only by having a vibrant, international HIA community that HIA practitioners can play a full part in helping to create a more sustainable, equitable and healthy world. ${ }^{25,26}$

\section{References}

1. Quigley R, den Broeder L, Furu P, Bond A, Cave B, Bos R. Health impact assessment international best practice principles. Special publication series no. 5. Fargo, USA: International Association for Impact Assessment, 2006.

2. Health impact assessment: main concepts and suggested approach. Gothenburg Consensus Paper. Brussels: World Health Organization Regional Office for Europe, European Centre for Health Policy, 1999.

3. A Report of the Federal/Provincial/Territorial Committee on Environmental and Occupational Health. Canadian Handbook of Health Impact Assessment Volumes 1-4. Health Canada, 2004.

4. Mittelmark M. Promoting social responsibility for health: health impact assessment and healthy public policy at the community level. Health Promot Internation 2001; 16(3): 269-74. doi:10.1093/heapro/16.3.269

5. Dannenberg A, Bhatia R, Cole PL, Dora C, Fielding JE, Kraft K et al. Growing the field of health impact assessment in the united states: an agenda for research and practice. Am J Public Health 2006; 96(2): 262-70. doi:10.2105/AJPH.2005.069880

6. Centers for Disease Control and Prevention. Health impact assessment. Available at http://www.cdc.gov/healthyplaces/ hia.htm, accessed 23 August 2007.

7. University of California. Los Angeles. Health impact assessment: information and insight for policy decisions. Available at http://www.ph.ucla.edu/hs/health-impact/, accessed 23 August 2007.

8. San Francisco Department of Health. Environmental Health Section. Eastern neighbourhoods community health impact assessment. Available at http://www.sfdph.org/phes/ ENCHIA.htm, accessed 23 August 2007.

9. University of Minnesota, Metropolitan Design Centre. Design for health. Available at http://www.designforhealth.net, accessed 23 August 2007.

10. Ståhl T, Wismar M, Ollila E, Lahtinen E, Leppo K. Health in all policies: prospects and potentials. Ministry of Social Affairs and Health, Finland and European Health Observatory on Health Systems and Policies 2006. Available from http://ec.europa.eu/health/ph_information/documents/health_in _all_policies.pdf

11. NHS Healthy Urban Development Unit. Available at http://www.healthyurbandevelopment.nhs.uk/, accessed 23 August 2007.
12. World Bank. Environmental assessment sourcebook and updates. 1991 to present. Available at http://go.worldbank.org/ LLF3CMS1I0, accessed 23 August 2007.

13. African Development Bank. Integrated environmental and social impact assessment guidelines. 2003. Available at http://www.afdb.org/pls/portal/url/ITEM/F813B8C92C4393E8 E030C00A0C3D1B93, accessed 23 August 2007.

14. Gasa N. Mainstreaming health impact assessment at the Development Bank of Southern Africa. Personal communication. 2007.

15. Towards a healthy society: healthy public policy and health impact assessment in Thailand. Health Systems Research Institute, Healthy Public Policy and Health Impact Assessment Program, 2005.

16. Phoolcharoen W, Sukkumnoed D, Kessomboon P. Development of health impact assessment in Thailand: recent experiences and challenges. Bull World Health Organ 2003; 81(6): 465-7.

17. Chanthaphone S. Health impact assessment development process in the Lao PDR. In 6th Global Conference on Health Promotion; 2005; Bangkok, Thailand.

18. Health Systems Research Unit. Thailand. Available at http://www.hsri.or.th/, accessed 23 August 2007.

19. Enhealth Council. Health impact assessment guidelines, 2001. Available from http://enhealth.nphp.gov.au/council/pubs/ pdf/hia_guidelines.pdf

20. Public Health Advisory Committee. An idea whose time has come new opportunities for health impact assessment in New Zealand public policy and planning. 2007. Available at http://www.phac.health.govt.nz/moh.nsf/indexcm/phac-ideawhose-time-has-come, accessed 23 August 2007.

21. University of New South Wales. Research Centre for Primary Health Care \& Equity. HIA Connect: building capacity for health impact assessment. Available at http://www.hiaconnect.edu.au/, accessed 23 August 2007.

22. Lock K, McKee M. Health impact assessment: assessing opportunities and barriers to intersectoral health improvement in an expanded European Union. J Epidemiol Community Health 2005; 59: 356-60. doi:10.1136/jech.2004.024026

23. Mindell J, Boaz A, Joffe M, Curtis S, Birley M. Enhancing the evidence base for health impact assessment. J Epidemiol Community Health 2004; 58: 546-51. doi:10.1136/jech.2003.012401

24. Krieger N, Northridge M, Gruskin S, Quinn M, Kriebel D, Davey Smith G et al. For the HIA "promise and pitfalls" conference group. Assessing health impact assessment: multidisciplinary and international perspectives. $J$ Epidemiol Community Health 2003; 57(9): 659-62. doi:10.1136/jech.57.9.659

25. University of New South Wales, Research Centre for Primary Health Care and Equity. HIA Connect: International HIA Blog. Available at http://healthimpactassessment.blogspot.com/, accessed 23 August 2007.

26. Vohra S. Health impact assessment community wiki. Available at www.healthimpactassessment.info, accessed 23 August 2007. 